\title{
Facile Synthesis of Single-Phase Alpha-Tungsten Nanopowders from Ammonium Paratungstate by RF Induction Thermal Plasma and Thermochemical Reduction
}

\author{
Dongyoon Shin, Hyun-Woo Shim, Basudev Swain, Kyung-Soo Park*, and Chan-Gi Lee* \\ Material Science \& Chemical Engineering Center, Institute for Advanced Engineering (IAE), Yongin 17180, Republic of Korea
}

\begin{abstract}
Facile, economic methods of preparing tungsten (W) nanopowder are critically needed to meet industrial demand. Herein, we report a method of preparing single-phase alpha-W $(\alpha-W)$ nanopowders using ammonium paratungstate (APT) as a starting material and the optimum synthesis conditions. The process involves two stages: i) the radio-frequency (RF) induction thermal plasma treatment of APT, followed by ii) thermochemical reduction at $600-900{ }^{\circ} \mathrm{C}$. The crystallographic phase and morphological evolution of all products were systematically investigated using X-ray diffraction (XRD), field emission scanning electron microscopy (FESEM), and transmission electron microscopy (TEM), and the effects of the annealing temperature on the phase and particle size of the obtained powders were also evaluated. When the RF induction thermal plasma treatment was conducted with and without $\mathrm{H}_{2}$, the XRD and FESEM results showed the formation of mixed-phase $\alpha$ - and beta-W $(\beta-\mathrm{W})$ nanopowder and $\mathrm{WO}_{3}$ nanopowder, respectively. Single-phase $\alpha-\mathrm{W}$ nanopowder was achieved by annealing the $\mathrm{WO}_{3}$ nanopowder in an $\mathrm{H}_{2}$ reductive atmosphere at $700^{\circ} \mathrm{C}$ for $10 \mathrm{~min}$, resulting in homogenous nanoparticles with a small particle size (d50) of $21.16 \mathrm{~nm}$ without any aggregation.
\end{abstract}

(Received July 14, 2020; Accepted September 9, 2020)

Keywords: alpha-tungsten, nanopowder, ammonium paratungstate (APT), RF induction thermal plasma, thermochemical reduction

\section{INTRODUCTION}

Fine metallic nanopowders have many advantages, including high hardness, toughness, and strength, and as a result have been intensively investigated and used extensively as raw materials in various industrial fields, including spaceflight, electronics, national defense, and engineering. Among various metallic nanopowder systems, tungsten (W) nanopowder has attracted great interest as a potential candidate for catalysis, hard materials, thermionic cathodes, and high-power batteries, because of its highly oxophilic characteristics [1]. However, at present, the production of metallic $\mathrm{W}$ powder is a complex multistep process involving the processing of $\mathrm{W}$ ore concentrates, in the following stages:

\footnotetext{
- 박경수·심현우·Basudev Swain·이찬기: 박사, 신동윤: 연구원

*Corresponding Author: Kyung-Soo Park

[Tel: +82-31-330-7422, E-mail: kspark@iae.re.kr]

*Corresponding Author: Chan-Gi Lee

[Tel: +82-31-330-7495, E-mail: cglee@iae.re.kr]

Copyright (c) The Korean Institute of Metals and Materials
}

(i) Separation of useful components from the $\mathrm{W}$ ore, (ii) Isolation of ammonium paratungstate or other compounds, (iii) Purification by reduction and finally, (iv) Metallic W production [2]. Compared with the several operational steps required for the production of $\mathrm{W}$ powders, a facile synthesis process to produce metallic $\mathrm{W}$ nanopowder would be an important development.

Nano-sized W powder synthesis is typically performed using one of two different approaches, top-down or bottomup routes. Approaches include mechanical milling [3-5], thermal decomposition [6], molten salt electrolysis [7], solution combustion synthesis [8], epitaxial growth [9], and chemical reaction [10]. However, due to a resistance to acids and alkalis, it is hard to produce $\mathrm{W}$ nanopowders, along with common techniques such as sol-gel, hydrothermal, chemical reaction, and conventional evaporation/condensation. Furthermore, the preparation of metallic $\mathrm{W}$ nanopowder requires substantial retooling of conventional processes, making the materials relatively costly and not amenable to 
mass production.

As an alternative method, the thermal plasma technique may be a suitable choice, and has been used by several authors for the synthesis of metallic W nanopowder [11-14]. The thermal plasma technique has several advantages to provide the materials with high temperature, good thermal and electrical conductivity, and other exotic properties and has been studied in a variety of applications, especially for the synthesis of various functional nanomaterials [15-19].

Among the different types of thermal plasmas, such as direct-current (DC) plasma, radio-frequency (RF) induction plasma (or inductively coupled plasma) has the unique advantages of a relatively large plasma volume, a lower plasma velocity, clean high-energy, and good chemical reactivity. RF induction thermal plasma is especially suitable for materials with high melting points because of its long residence time, and has been extensively used for the synthesis of ultrafine powders, spheroidization, and deposition [11, 12, 14, 17-22]. Krasovskii et al. reported the production of alpha$\mathrm{W}(\alpha-\mathrm{W})$ in a DC plasma reactor from an oxide feedstock [13]. Ryu et al. reported the production of $\mathrm{W}$ nanopowder with a particle size $(\mathrm{d} 50)$ of $88.5 \mathrm{~nm}$ using a thermal plasma process with ammonium paratungstate (APT) [12]. Sarmah et al. reported a $\mathrm{W}$ nanopowder synthesis using a plasma expansion technique with $\mathrm{W}$ trioxide $\left(\mathrm{WO}_{3}\right)$ in which $\mathrm{H}_{2}$ gas was used as a reductant [11]. Enneti et al. investigated the synthesis of nanocrystalline $\mathrm{W}$ in a single step via a thermal plasma technique [14]. Elsewhere, we have reported the synthesis of nanopowder by RF induction plasma using three different precursor materials, commercial tungsten, tungsten trioxide, and APT [23].

$\mathrm{W}$ has both a stable alpha-W $(\alpha-\mathrm{W})$ phase and metastable beta-W $(\beta-\mathrm{W})$ phase. The $\alpha-\mathrm{W}$ phase has a body-centeredcubic (bcc) structure and is highly preferred because it exhibits better properties (e.g., higher electrical conductivity, and better mechanical strength) than the $\beta-\mathrm{W}$ phase [24]. The $\beta-\mathrm{W}$ phase has a primitive cubic (A15) and a non-equilibrium crystalline structure. Although the $\alpha-\mathrm{W}$ phase is preferred to the $\beta-\mathrm{W}$ phase, the formation of mixed-phase $\alpha$ - and $\beta-\mathrm{W}$ nanostructures have been frequently reported in the synthesis of W-based nanoparticles and thin films [11, 12, $17,25-28$ ], indicating that the preparation of $\alpha-\mathrm{W}$ singlephase nanostructures is not easy.
In our current study, single-phase $\alpha-\mathrm{W}$ nanopowders were synthesized from commercial APT powder in a two-stage process. First, $\mathrm{WO}_{3}$ nanopowder was synthesized by $\mathrm{RF}$ induction thermal plasma treatment of the APT. Secondly, the $\mathrm{WO}_{3}$ nanopowder was annealed in an $\mathrm{H}_{2}$ atmosphere to reduce it to a single-phase $\alpha-\mathrm{W}$ nanopowder. One should not confuse the present investigation with our research reported elsewhere [23]. The previous research compared three different precursors for synthesis and explored the possibility of single-phase $\alpha-\mathrm{W}$ nanopowder synthesis. Our current investigation utilizes two findings from the prior study ((i) that APT in the absence of $\mathrm{H}_{2}$ produces $\mathrm{WO}_{3}$ powder and (ii) $\mathrm{WO}_{3}$ powder under $\mathrm{H}_{2}$ atmosphere can produce $\mathrm{W}$ nanopowders) to synthesize single-phase $\alpha-\mathrm{W}$ nanopowder. The present process is completely dry and was carried out without any chemicals except $\mathrm{Ar}$ and $\mathrm{H}_{2}$.

The characteristics of the synthesized nanopowders were investigated using X-ray diffraction (XRD), field emission scanning electron microscopy (FESEM), and transmission electron microscopy (TEM). Although a few metallic singlephase $\alpha-\mathrm{W}$ nanostructures have been reported, to the best of our knowledge, the preparation of a single-phase $\alpha-W$ nanopowder via such a simple process (i.e., a combination of thermal plasma treatment and thermochemical reduction) has not yet been reported. Moreover, the particle size of the single-phase $\alpha-\mathrm{W}$ nanopowder was easily controlled by the annealing temperature in the thermochemical reduction of the $\mathrm{WO}_{3}$ nanopowder. The novelty of the current research is summarized below.

(i) Problems reported in earlier research [23], like mixedphase $\mathrm{W}$ nanopowder synthesis, were overcome.

(ii) Utilizing commercially available APT, and a two-step $\mathrm{RF}$ induction thermal plasma treatment process, pure singlephase $\alpha-\mathrm{W}$ nanopowder can be synthesized for commercial applications.

(iii) An important material process engineering challenge has been successfully addressed through the current investigation.

\section{Experimental}

\subsection{Materials}

Commercial ammonium paratungstate (APT; $\left(\mathrm{NH}_{4}\right)_{10} \mathrm{H}_{2}$ $\mathrm{W}_{12} \mathrm{O}_{42}\left(\mathrm{H}_{2} \mathrm{O}\right)_{4}$, Ganzhou Grand Sea W\&Mo Group Co., 
LTD) powder and commercial $\mathrm{WO}_{3}$ powder (Ganzhou Grand Sea W\&Mo Group Co., LTD) was used without further purification as the precursors for the synthesis of single-phase $\alpha-\mathrm{W}$ nanopowder. Ar (99.999\% purity) was used as the central gas, sheath gas, carrier gas, and quenching gas in the $\mathrm{RF}$ induction thermal plasma system. Whenever needed, $\mathrm{H}_{2}$ (99.999\% purity) was used along with $\mathrm{Ar}$ as the reducing agent.

\subsection{Configuration of the RF induction thermal plasma system}

The RF induction thermal plasma system consisted of an RF power supply (30 kW, $4 \mathrm{MHz}$ ), a plasma torch, a reactor chamber, a powder-feeding system, and powder-collecting sintered-metal filters. A more detailed configuration of the RF induction thermal plasma system is provided in Fig. 1.

\subsection{Synthesis of single-phase $\alpha-W$ nanopowder}

Single-phase $\alpha-W$ nanopowder was synthesized in a twostage process through RF induction thermal plasma treatment using ATP as a precursor. Initially, in the first step of the RF induction thermal plasma treatment process, the precursor APT was injected into the RF induction thermal plasma

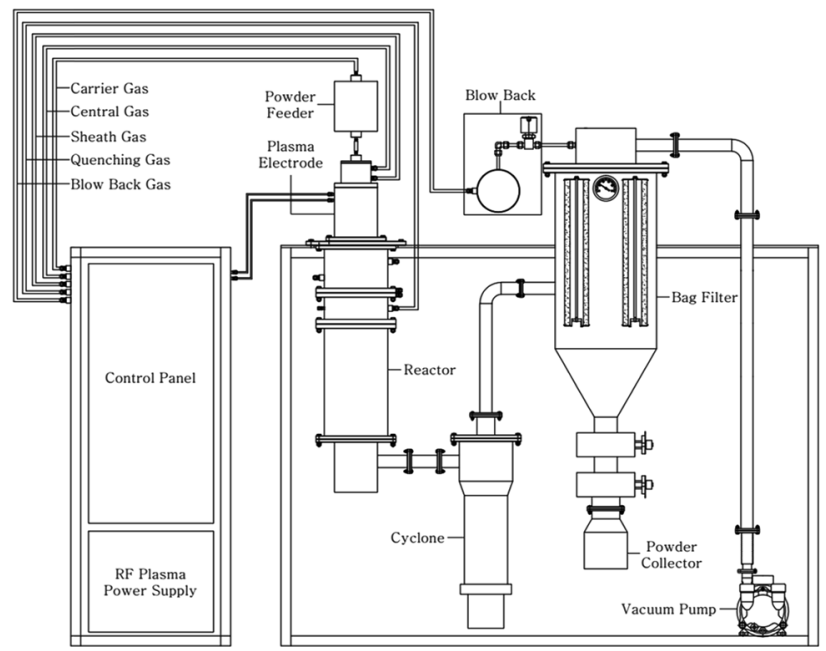

Fig. 1. Schematic of RF induction thermal plasma system. under the experimental conditions listed in Table 1. In the table, "Sheath gas of 50 SLPM (Ar) +0 SLPM $\left(\mathrm{H}_{2}\right)$ " corresponds to Ar sheath gas without $\mathrm{H}_{2}$. Before the precursor was injected, the reactor chamber was purged with Ar for 30 min and pre-conditioned to the plasma power as indicated in Table 1 for $20 \mathrm{~min}$, until the system reached a steady level. The precursor particles were carried into the plasma flame with the carrier gas by the powder-feeding system, vaporized by the plasma flame, and quenched rapidly by the quenching gas to accelerate the nucleation kinetics of the nanoparticle synthesis. The synthesized nanoparticles were collected using powder-collecting sintered-metal filters (pore size $=1 \mu \mathrm{m}$ ). In the second step, the thermochemical reduction process, the nanopowder synthesized in the first step by RF induction thermal plasma was annealed in an $\mathrm{H}_{2}$ reductive atmosphere. The conditions for $\mathrm{H}_{2}$ reductive annealing were an $\mathrm{H}_{2}$ flow rate of $0.5 \mathrm{~L} / \mathrm{min}$, Temperature of $600-900^{\circ} \mathrm{C}$ and $10 \mathrm{~min}$ process time.

\subsection{Characterization}

The morphology of all the as-synthesized nanopowders was analyzed using field emission scanning electron microscopy (FESEM; JSM-6700F, JEOL, Japan) and high-resolution transmission electron microscopy (HRTEM; JEM-2100F, JEOL, Japan) along with energy dispersive X-ray spectrometry (EDX). The phase compositions of the nanopowders were analyzed using X-ray diffraction (XRD; XRD-6100F, Shimadzu, Japan), and their particle sizes were determined from their FESEM images. The thermal characteristics of the APT precursor were analyzed by thermogravimetric/ differential thermal analysis (TG/DTA; DTG-60H, Shimadzu, Japan) in an Ar atmosphere.

\section{RESULTS AND DISCUSSION}

The crystallinity, morphology, and thermal characteristics of the APT precursor were analyzed using XRD, FESEM, and TG/DTA, as shown in Fig. 2. The XRD pattern of the

Table 1. Experimental conditions of RF induction thermal plasma treatment.

\begin{tabular}{ccccccr}
\hline Plasma power & Precursor feed & Atmospheric & \multicolumn{3}{c}{ Plasma gas [SLPM] } \\
\cline { 4 - 7 } & rate $[\mathbf{g} / \mathbf{m i n}]$ & pressure $[\mathbf{p s i a}]$ & Sheath gas & Central gas & Carrier gas & Quenching gas \\
\hline 25 & 10 & 14.7 & $50(\mathrm{Ar})+0$ or $5\left(\mathrm{H}_{2}\right)$ & $20(\mathrm{Ar})$ & $10(\mathrm{Ar})$ & $80(\mathrm{Ar})$ \\
\hline
\end{tabular}



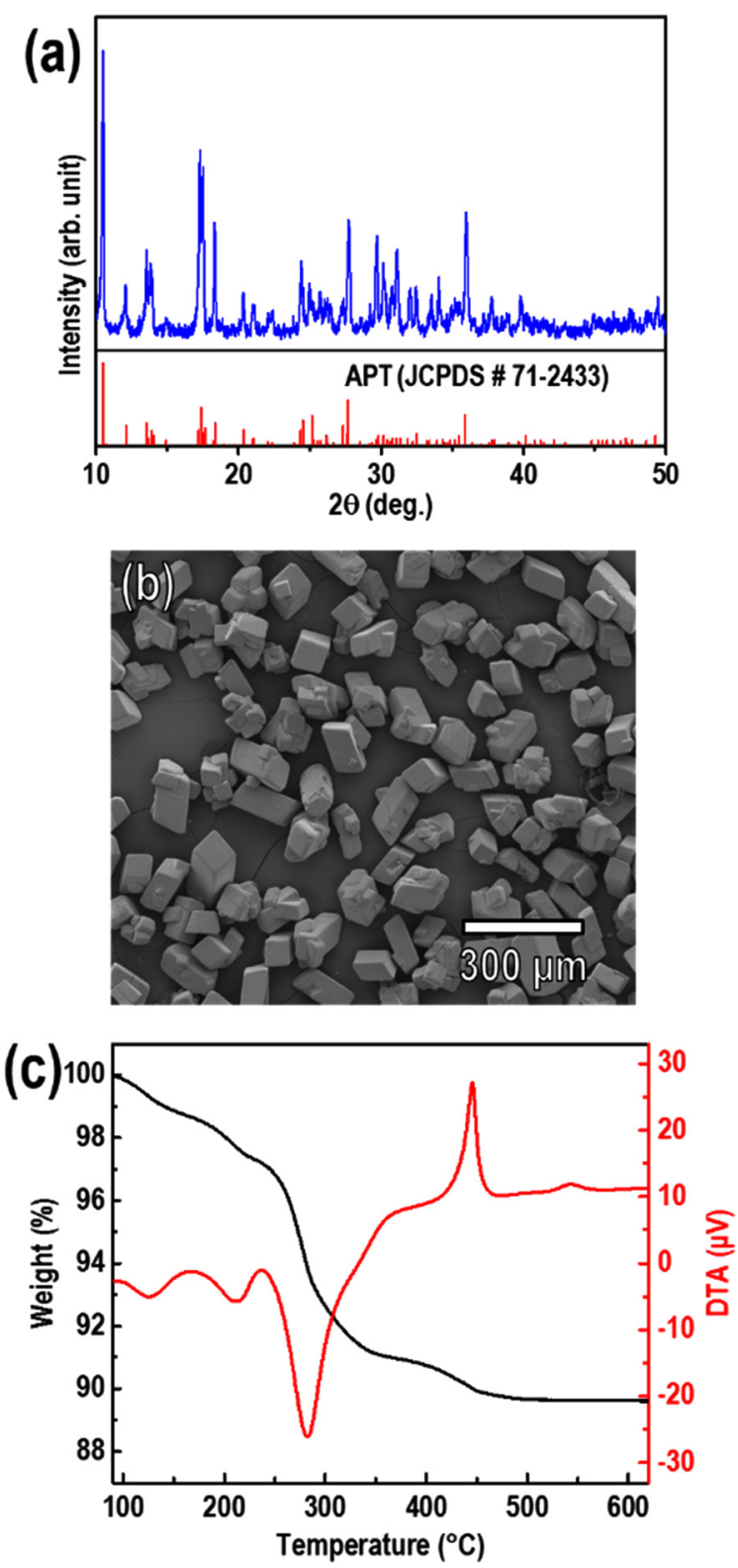

Fig. 2. (a) XRD pattern, (b) SEM image, and (c) TG/DTA result of the APT precursor.

APT was indexed to monoclinic APT (JCPDS No. 71-2433), the APT consisted of microsized particles (micro-particles) with an average particle size (median diameter, d50) of $83.85 \mu \mathrm{m}$. The TG/DTA results showed that the complete decomposition of APT and crystallization as $\mathrm{WO}_{3}$ occurred before the temperature reached $600{ }^{\circ} \mathrm{C}$. This result is in good agreement with prior reports about the thermogravimetric analysis of APT $[12,17,29,30]$, which indicated that the decomposition process mainly consisted of the loss of $\mathrm{H}_{2} \mathrm{O}$

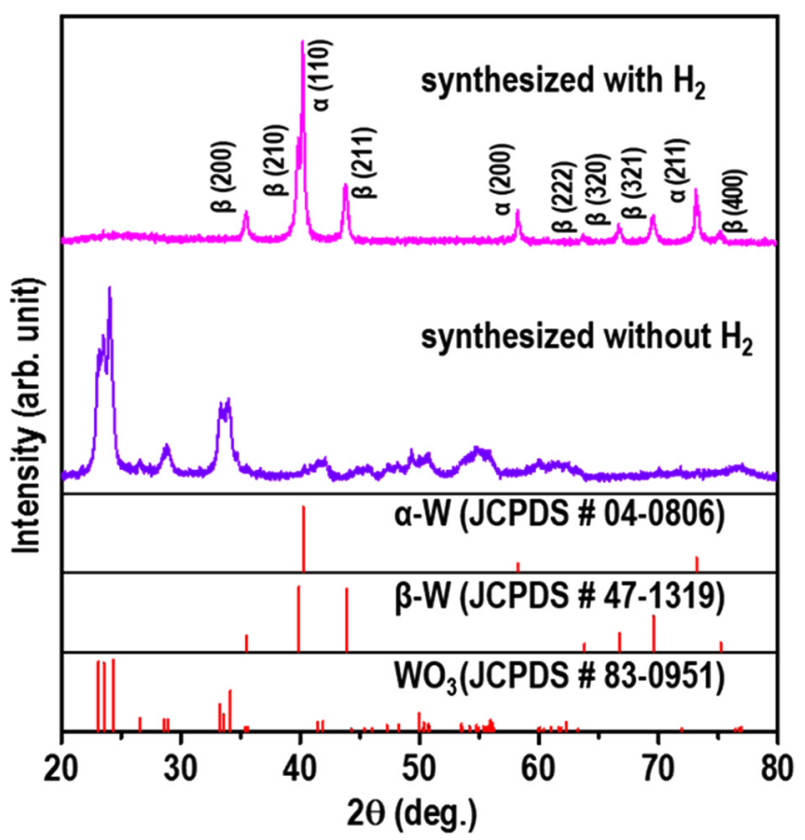

Fig. 3. XRD patterns of powders synthesized by RF induction thermal plasma treatment of the APT precursor with and without $\mathrm{H}_{2}$.

and $\mathrm{NH}_{3}$ before reaching $500{ }^{\circ} \mathrm{C}$, and fully crystallized $\mathrm{WO}_{3}$ phase was formed. In a typical RF induction thermal plasma system, the temperature of the plasma flame reaches up to $12,000 \mathrm{~K}$ and thus is sufficient for the decomposition of the APT precursor.

The phase compositions of the powders synthesized from the APT precursor by RF induction thermal plasma with and without $\mathrm{H}_{2}$ are presented in Fig. 3. The XRD peaks of the powder synthesized without $\mathrm{H}_{2}$ (Ar only, inert atmosphere) were indexed to monoclinic $\mathrm{WO}_{3}$ (JCPDS No. 83-0951). When APT was injected into the high-temperature jet zone of the RF induction thermal plasma, it was thermally decomposed and evaporated immediately to produce the $\mathrm{WO}_{3}$ powder in an inert atmosphere (Ar). This is a typical plasma-enhanced chemical vapor reaction.

The XRD peaks of the powder synthesized in the presence of $\mathrm{H}_{2}\left(\mathrm{Ar}\right.$ atmosphere with $\left.10 \% \mathrm{H}_{2}\right)$ were indexed to a mixture of the $\alpha-\mathrm{W}$ (JCPDS No. 04-0806) and $\beta-\mathrm{W}$ (JCPDS No. 47-1319) phases. Thus, the addition of the reducing agent $\mathrm{H}_{2}$ to the Ar atmosphere caused the mixed-phase $\alpha$ and $\beta-\mathrm{W}$ powder to be produced rather than $\mathrm{WO}_{3}$. The powder consisted mainly of the stable $\alpha-\mathrm{W}$ phase with the 
metastable $\beta-\mathrm{W}$ phase as the minor phase. The ratio of the fraction of the $\beta-\mathrm{W}$ phase to the $\alpha-\mathrm{W}$ phase in the $\mathrm{W}$ powder was calculated as the diffraction intensity ratio $\left(\boldsymbol{R}_{\beta-\mathrm{W}}\right)$ of the main peak of the $\beta-\mathrm{W}$ phase, $\beta-\mathrm{W}(210)\left(\boldsymbol{I}_{\beta-\mathrm{W}}\right)$, to that of the $\alpha-\mathrm{W}$ phase, $\alpha-\mathrm{W}$ (110) $\left(\boldsymbol{I}_{\alpha-\mathrm{W}}\right)[9]$ :

$$
\boldsymbol{R}_{\beta-\mathrm{W}}=\boldsymbol{I}_{\beta-\mathrm{W}} / \boldsymbol{I}_{\alpha-\mathrm{W}}
$$

The $\boldsymbol{R}_{\beta-\mathrm{W}}$ of the W powder was calculated using Equation (1) and the value was 0.35 , indicating that the $\alpha-W$ phase comprised $74 \%$ of the $\mathrm{W}$ powder.

The morphology and crystallinity of the $\mathrm{WO}_{3}$ and $\mathrm{W}$ powders synthesized using RF induction thermal plasma was investigated using FESEM, HRTEM, and selected area electron diffraction (SAED), as shown in Fig. 4. The $\mathrm{WO}_{3}$ powder synthesized without $\mathrm{H}_{2}$ consisted of nanoparticles with a particle size $(\mathrm{d} 50)$ of $22.10 \mathrm{~nm}$; the nanoparticles had irregular shapes without an outer shell (Fig. 4a-1 and a-2). The HRTEM image corresponding to the region marked by the red square in Fig. $4 \mathrm{a}-2$ shows that individual $\mathrm{WO}_{3}$ nanopowder particles had a single-crystalline phase (Fig. 4a3 ). The measured lattice spacing of 3.8 corresponds to the $d$ spacing between the (002) planes of $\mathrm{WO}_{3}$ (Fig. 4a-3). The SAED pattern shown in Fig. 4a-4 also confirmed that the nanopowder exhibited the monoclinic $\mathrm{WO}_{3}$ phase, which was consistent with the XRD results (Fig. 3).
The $\mathrm{W}$ powder synthesized in the presence of $\mathrm{H}_{2}$ consisted of nanoparticles with a particle size (d50) of $20.34 \mathrm{~nm}$ and approximately spherical shape with a core-shell morphology (Fig. 4b-1 and b-2). The HRTEM image corresponding to the region marked by the red square in Fig. 4b-2 showed a measured lattice spacing of 2.2 , which corresponds to the $d$ spacing between the (110) planes of $\alpha-W$ (Fig. 4b-3). The SAED patterns shown in Fig. $4 b-4$ confirmed that the nanopowder consisted mainly of the $\alpha-\mathrm{W}$ phase with $\beta-\mathrm{W}$ as the minor phase, which was consistent with the XRD results (Fig. 3).

One explanation for why the $\beta-\mathrm{W}$ phase formed along with the $\alpha-\mathrm{W}$ phase when $\mathrm{W}$ nanoparticles were synthesized with $\mathrm{H}_{2}$ (Fig. 3 and Fig. 4b) is that impurities, especially oxygen, can promote the formation of the $\beta-\mathrm{W}$ phase during nucleation and growth $[20,31,32]$. The transformation from the $\beta-\mathrm{W}$ phase into the $\alpha-\mathrm{W}$ phase is thermally activated; the oxygen impurities diffuse away and long-range ordering occurs [25]. The presence of the $\beta-\mathrm{W}$ phase in the $\mathrm{W}$ nanopowder is proof of the incomplete reduction of the $\mathrm{W}$ oxides, or recombination of $\mathrm{W}$ and oxygen impurities during the process [20]. This could be because there was insufficient time for the thermal decomposition and reduction of the APT precursor particles in the high-temperature jet zone of the RF induction thermal plasma.

Some other reports have also explained that there is a

(a) synthesized without $\mathrm{H}_{2}$

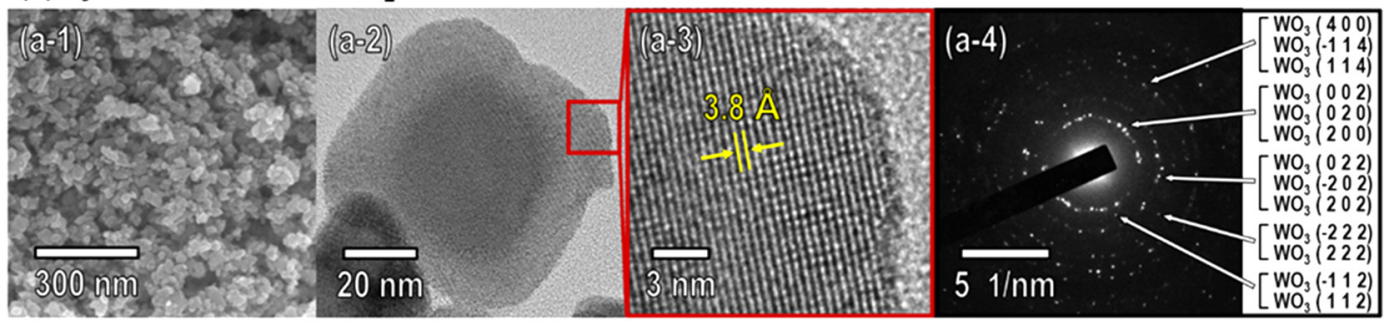

(b) synthesized with $\mathrm{H}_{2}$

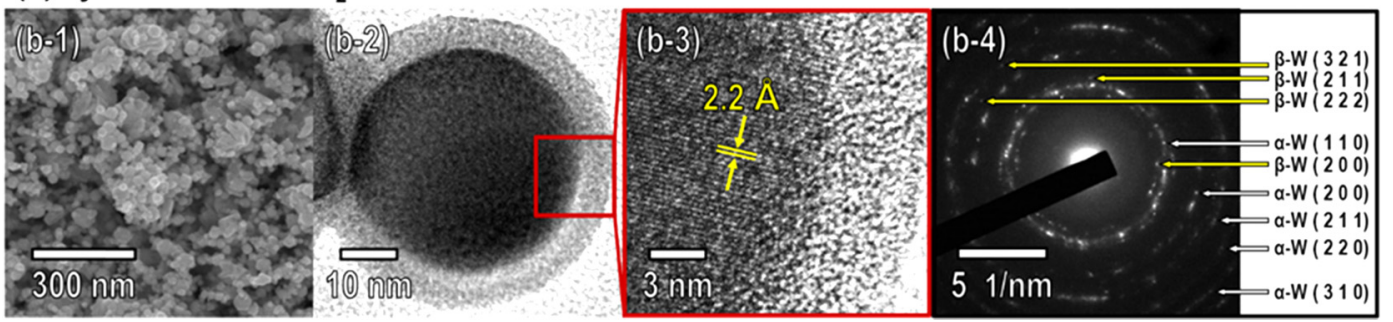

Fig. 4. Microstructural characteristics of powders synthesized by RF induction thermal plasma treatment of the APT precursor with and without $\mathrm{H}_{2}$. (a-1 and b-1) FESEM images, (a-2 and b-2) low-magnification TEM observation of an individual nanoparticle, (a-3 and b-3) HRTEM images corresponding to the red square of (a-3 and b-3), respectively. (a-4 and b-4) SAED patterns. 
higher chance of forming the $\beta-\mathrm{W}$ phase with a smaller $\mathrm{W}$ nanoparticle grain size $[33,34]$. If so, synthesizing $W$ nanoparticles by RF induction thermal plasma is attended by a high chance of forming the $\beta-\mathrm{W}$ phase. Thus, a posttreatment to transform the $\beta-\mathrm{W}$ phase of the $\mathrm{W}$ nanopowder synthesized with $\mathrm{H}_{2}$ into the $\alpha-\mathrm{W}$ phase, or to transform the $\mathrm{WO}_{3}$ nanopowder synthesized without $\mathrm{H}_{2}$ into $\alpha-\mathrm{W}$ nanopowder without the $\beta-\mathrm{W}$ phase, is indispensable for the preparation of single-phase $\alpha-\mathrm{W}$ nanopowder.

To investigate the phase transformation from $\mathrm{WO}_{3}$ into $\mathrm{W}$ by thermochemical reduction, samples of the $\mathrm{WO}_{3}$ nanopowder synthesized by RF induction thermal plasma were reduced by annealing at $600-900{ }^{\circ} \mathrm{C}$ in an $\mathrm{H}_{2}$ atmosphere for $10 \mathrm{~min}$. It is known that $\mathrm{WO}_{3}$ is reduced to $\mathrm{W}$ in an $\mathrm{H}_{2}$ atmosphere which can be explained using Equation (2-5) [2]:

$$
\begin{aligned}
& \mathrm{WO}_{3}(\mathrm{~s})+0.1 \mathrm{H}_{2}(\mathrm{~g}) \rightleftarrows \mathrm{WO}_{2.9}(\mathrm{~s})+0.1 \mathrm{H}_{2} \mathrm{O} \\
& \mathrm{WO}_{2.9}(\mathrm{~s})+0.18 \mathrm{H}_{2}(\mathrm{~g}) \rightleftarrows \mathrm{WO}_{2.72}(\mathrm{~s})+0.18 \mathrm{H}_{2} \mathrm{O} \\
& \mathrm{WO}_{2.72}(\mathrm{~s})+0.72 \mathrm{H}_{2}(\mathrm{~g}) \rightleftarrows \mathrm{WO}_{2}(\mathrm{~s})+0.72 \mathrm{H}_{2} \mathrm{O} \\
& \mathrm{WO}_{2}(\mathrm{~s})+2 \mathrm{H}_{2}(\mathrm{~g}) \rightleftarrows \mathrm{W}(\mathrm{s})+2 \mathrm{H}_{2} \mathrm{O}
\end{aligned}
$$

The XRD patterns presented in Fig. 5 show that the powders reduced at $700{ }^{\circ} \mathrm{C}, 800{ }^{\circ} \mathrm{C}$, and $900{ }^{\circ} \mathrm{C}$ could be indexed to single-phase $\alpha-\mathrm{W}$ and were free of any peaks corresponding to $\mathrm{W}$ oxides or $\beta-\mathrm{W}$. As the temperature for annealing was increased from $700{ }^{\circ} \mathrm{C}$ to $900{ }^{\circ} \mathrm{C}$, the main peak of the $\alpha-\mathrm{W}$ phase, $\alpha-\mathrm{W}$ (110), became sharper, which was attributed to increased crystallinity and particle size due to the higher annealing temperature.

On the other hand, the pattern of the powder reduced at $600{ }^{\circ} \mathrm{C}$ corresponded mainly to the $\alpha-\mathrm{W}$ phase, but $\beta-\mathrm{W}$ was present as the minor phase. The $R_{\beta-\mathrm{W}}$ of the powder calculated with Eq. (1) was 0.22 , indicating that the $\alpha-W$ phase accounted for $18 \%$ of the $\mathrm{W}$ powder.

These XRD results indicate that some fraction of $\mathrm{WO}_{3}$ was transformed into the $\beta-\mathrm{W}$ phase via annealing at $600{ }^{\circ} \mathrm{C}$, while at the higher temperature $\left(700-900{ }^{\circ} \mathrm{C}\right)$ the $\mathrm{WO}_{3}$ was completely transformed into the $\alpha-\mathrm{W}$ phase.

The changes in the morphology of the powders reduced via thermochemical reduction were analyzed with FESEM, as

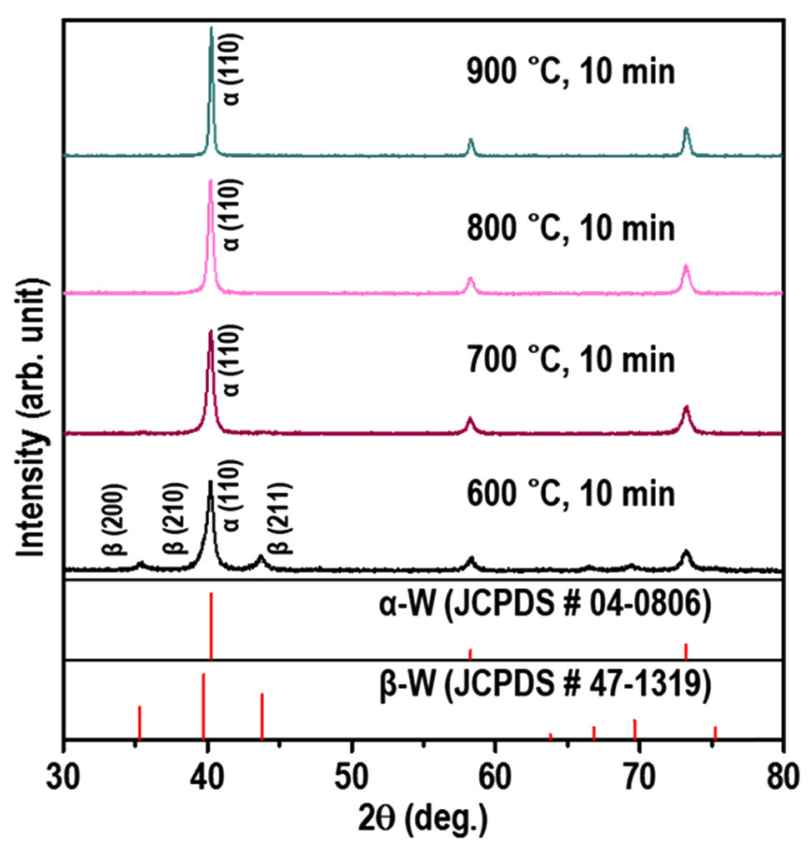

Fig. 5. XRD patterns of powders reduced at $600{ }^{\circ} \mathrm{C}, 700{ }^{\circ} \mathrm{C}, 800{ }^{\circ} \mathrm{C}$, and $900{ }^{\circ} \mathrm{C}$ for $10 \mathrm{~min}$ from the $\mathrm{WO}_{3}$ nanopowder synthesized by $\mathrm{RF}$ induction thermal plasma treatment of the APT precursor without $\mathrm{H}_{2}$.

shown in Fig 6. The powders reduced at $600{ }^{\circ} \mathrm{C}$ (Fig. 6a) and $700{ }^{\circ} \mathrm{C}$ (Fig. 6b) had particle sizes (d50) of $20.51 \mathrm{~nm}$ and $21.16 \mathrm{~nm}$, respectively, which were not significantly different from that of the as-synthesized $\mathrm{WO}_{3}$ nanopowder. However, the powders reduced at $800{ }^{\circ} \mathrm{C}$ (Fig. 6c) and $900{ }^{\circ} \mathrm{C}$ (Fig. 6d) contained particles that had agglomerated to form larger

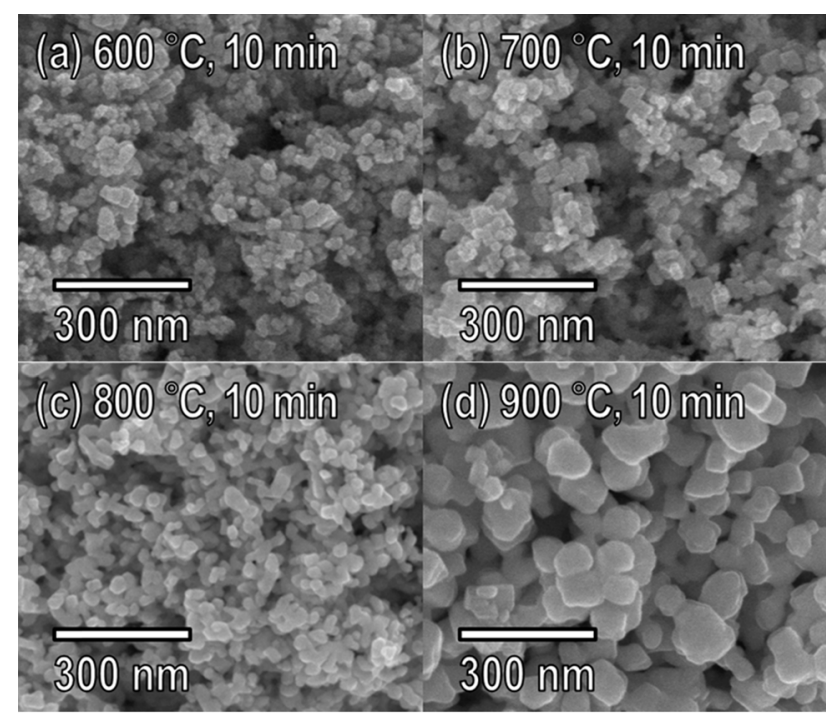

Fig. 6. FESEM images of powders reduced at (a) $600{ }^{\circ} \mathrm{C}$, (b) $700{ }^{\circ} \mathrm{C}$, (c) $800{ }^{\circ} \mathrm{C}$, and (d) $900{ }^{\circ} \mathrm{C}$ for $10 \mathrm{~min}$ from $\mathrm{WO}_{3}$ nanopowder synthesized using RF induction thermal plasma. 

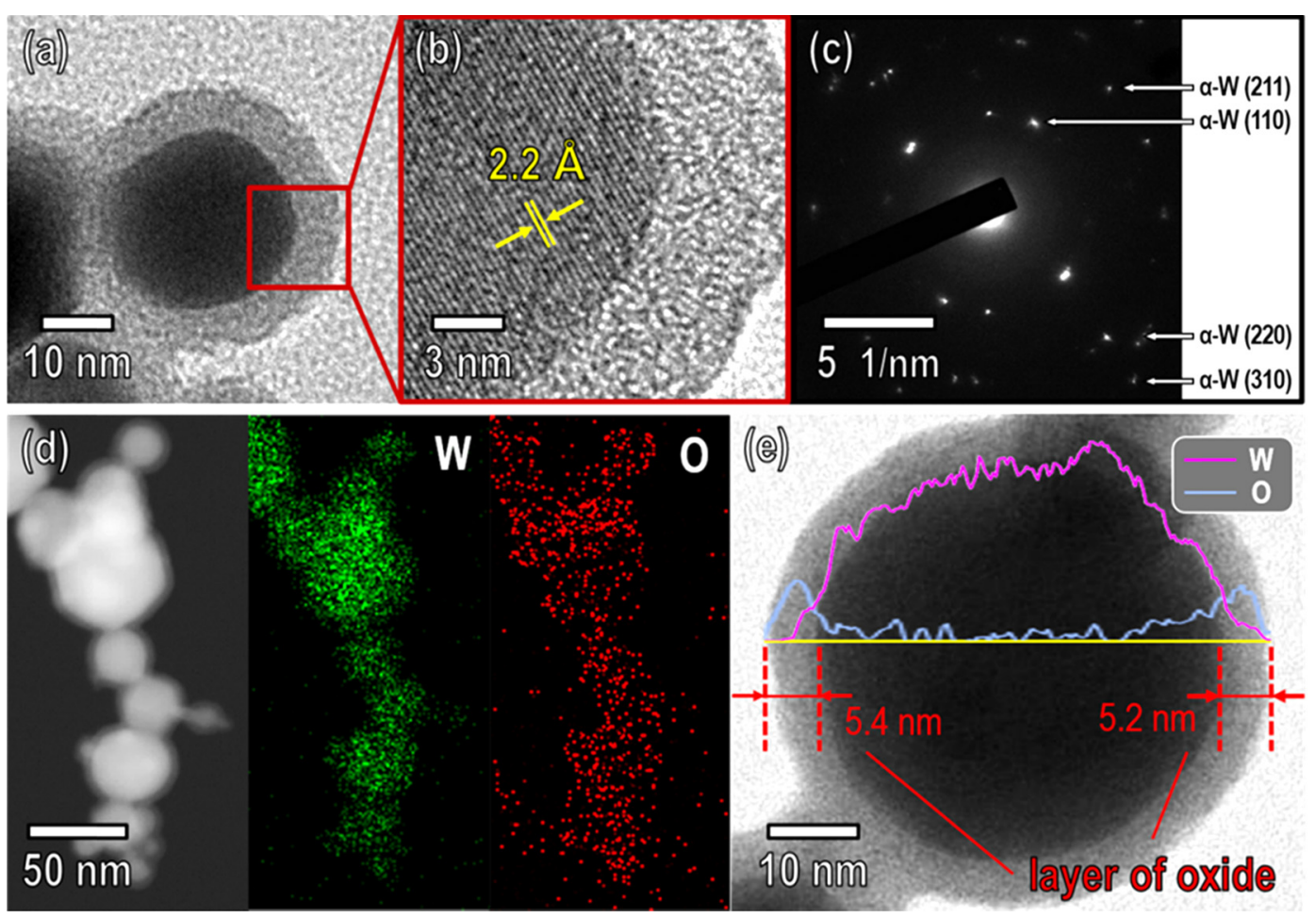

Fig. 7. TEM observations of the $\alpha-\mathrm{W}$ nanoparticles reduced at $700{ }^{\circ} \mathrm{C}$ for $10 \mathrm{~min}$. (a) Low-magnification micrograph, (b) HRTEM image corresponding to the red square in (a), (c) SAED pattern, (d, e) EDX elemental mapping and line scan profile.

particles. The particle size varied dramatically with the annealing temperature, and as a result the XRD peaks sharpened as annealing temperature increased. The atomic composition was also analyzed by EDX before and after the thermochemical reduction. The powder reduced by annealing at $700{ }^{\circ} \mathrm{C}$ for $10 \mathrm{~min}$ was almost completely transformed from $\mathrm{WO}_{3}$ into $\mathrm{W}$, with the oxygen content from $\mathrm{WO}_{3}$ being reduced from $29.2 \mathrm{wt} \%$ to $0.9 \mathrm{wt} \%$.

The morphology, crystallinity, and elemental distribution of the $\mathrm{W}$ nanopowder reduced by thermochemical reduction at $700{ }^{\circ} \mathrm{C}$ for $10 \mathrm{~min}$ were further investigated using HRTEM, SAED, elemental mapping, and line scan profile, as shown in Fig. 7. Fig. 7a shows that the $\mathrm{W}$ nanopowder had a spherical shape with a diameter of $\sim 35 \mathrm{~nm}$ and was surrounded by an amorphous oxide shell with a thickness of $\sim 5.4 \mathrm{~nm}$, which allowed the $\mathrm{W}$ nanopowder to be easily handled in air.

The HRTEM image corresponding to the region marked by the red square in Fig. 7a shows that the individual W nanopowder particles were single-crystalline and $\alpha-\mathrm{W}$ phase (Fig. 4b). The periodic lattice fringes indicated an interatomic plane distance of $2.2 \AA$, which agreed with the (110) plane of the $\alpha-W$ phase (Fig. 7b). The SAED patterns shown in Fig. 7c also confirmed that the $\mathrm{W}$ nanopowder consisted solely of the bcc structure $\alpha-\mathrm{W}$ phase without any $\beta-\mathrm{W}$ or $\mathrm{W}$ oxide phase, consistent with the XRD results (Fig. 5). The elemental mapping and line scan profile data taken from the reduced $\mathrm{W}$ nanopowder, shown in Fig. $7 \mathrm{~d}$ and Fig. 7e, verified that the nanopowder consisted only of the element $\mathrm{W}$ with an outer oxide shell, indicating that no oxygen atoms diffused into the $\mathrm{W}$ nanoparticles during the thermochemical reduction. The line scan profile data also shows that oxygen was present on the surface of the $\mathrm{W}$ nanoparticle. This means that the $0.9 \mathrm{wt} \%$ oxygen content detected by EDX was not due to the presence of $\mathrm{W}$ oxides inside the $\mathrm{W}$ nanoparticles, but instead to the amorphous oxide shells covering the surface of the pure metal W nanoparticles.

From Fig. 5 and Fig. 6, annealing the $\mathrm{WO}_{3}$ nanopowder at $600{ }^{\circ} \mathrm{C}$ formed the $\beta-\mathrm{W}$ phase, but not at $700-900{ }^{\circ} \mathrm{C}$. Thus, it is highly feasible that the $\beta-\mathrm{W}$ phase in $\mathrm{W}$ nanopowders can be transformed into the $\alpha-\mathrm{W}$ phase by annealing at high temperature $\left(700{ }^{\circ} \mathrm{C}\right)$ in an $\mathrm{H}_{2}$ atmosphere. This is in good agreement with the work of É. Hegedüs et al. [32], who 

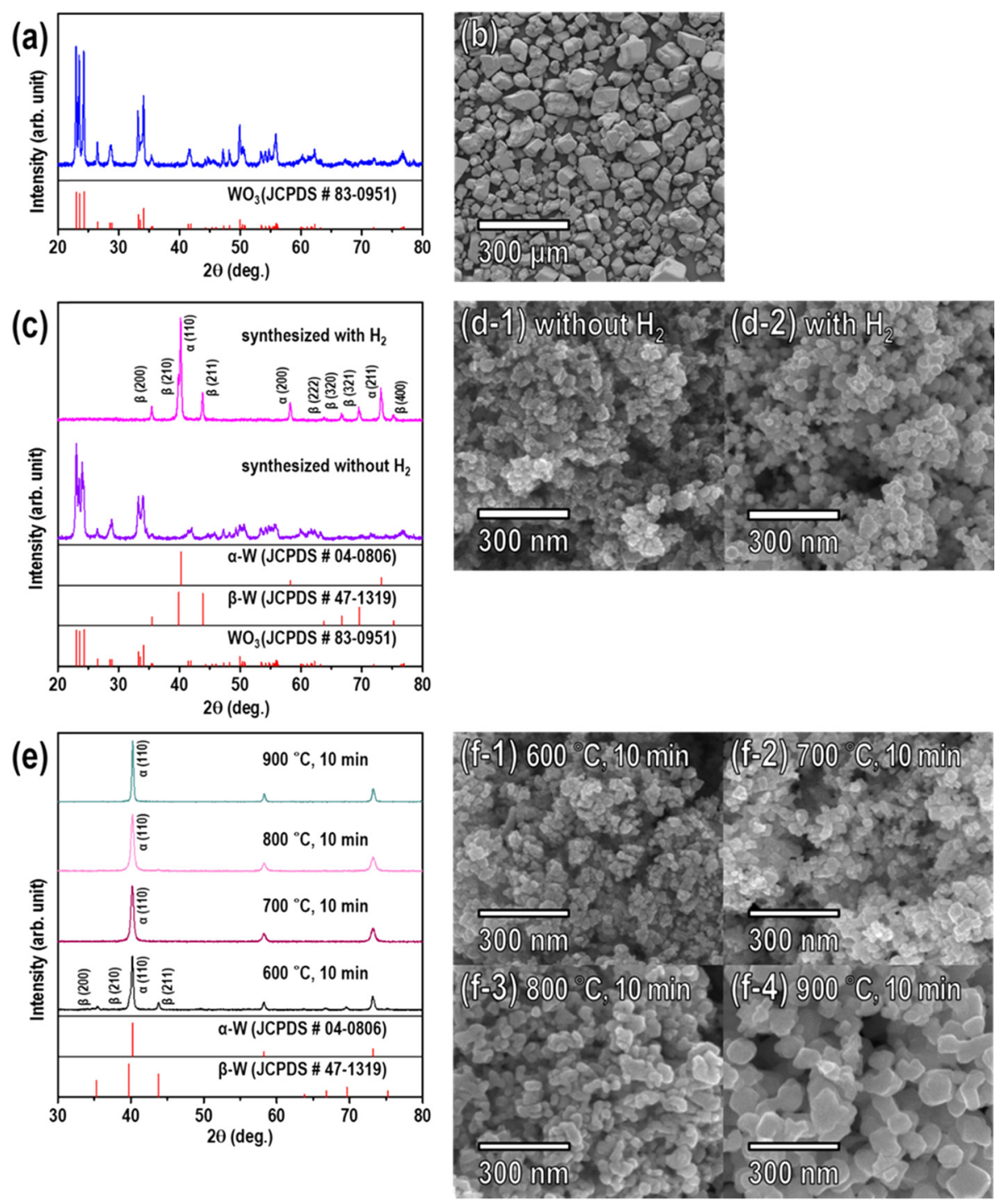

Fig. 8. (a) XRD pattern and (b) SEM image of the $\mathrm{WO}_{3}$ precursor, (c) XRD patterns and (d) FESEM images of powders synthesized by RF induction thermal plasma treatment of the $\mathrm{WO}_{3}$ precursor with and without $\mathrm{H}_{2}$, (e) XRD patterns and (f) FESEM images of powders reduced at $600{ }^{\circ} \mathrm{C}, 700{ }^{\circ} \mathrm{C}, 800{ }^{\circ} \mathrm{C}$, and $900{ }^{\circ} \mathrm{C}$ for $10 \mathrm{~min}$ from the $\mathrm{WO}_{3}$ nanopowder synthesized by $\mathrm{RF}$ induction thermal plasma treatment of the $\mathrm{WO}_{3}$ precursor without $\mathrm{H}_{2}$.

reported that the $\beta-\mathrm{W}$ phase was produced by the hydrogen reduction of $\mathrm{W}$ oxides at $500-640^{\circ} \mathrm{C}$, and that of Y.G. Shen et al. [31], who reported that the $\beta-\mathrm{W}$ phase was completely transformed into the $\alpha-\mathrm{W}$ phase by annealing at $900 \mathrm{~K}$ $\left(623^{\circ} \mathrm{C}\right)$. Accordingly, single-phase $\alpha-\mathrm{W}$ nanopowder can be obtained by the thermochemical reduction of $\mathrm{WO}_{3}$ nanopowder, and the particle size can be controlled by annealing temperature.

The same experiments were next performed using commercial $\mathrm{WO}_{3}$ powder as a precursor for the synthesis of the single-phase $\alpha-W$ nanopowder for comparison. The results are shown in Fig. 8. The results of both the RF induction thermal plasma treatment and the thermochemical reduction using the $\mathrm{WO}_{3}$ precursor were greatly similar to those using the APT precursor. Since APT is generally made from tungsten ore and used as a precursor for $\mathrm{WO}_{3}$, producing $\mathrm{W}$ nanopowders from APT in a single step is more economical than doing so from $\mathrm{WO}_{3}$.

Additionally, to investigate the thermochemical reduction behavior of the $\beta-\mathrm{W}$ to $\alpha-\mathrm{W}$ transformation, samples of the mixed-phase $\alpha$ - and $\beta$-W nanopowder synthesized by RF 

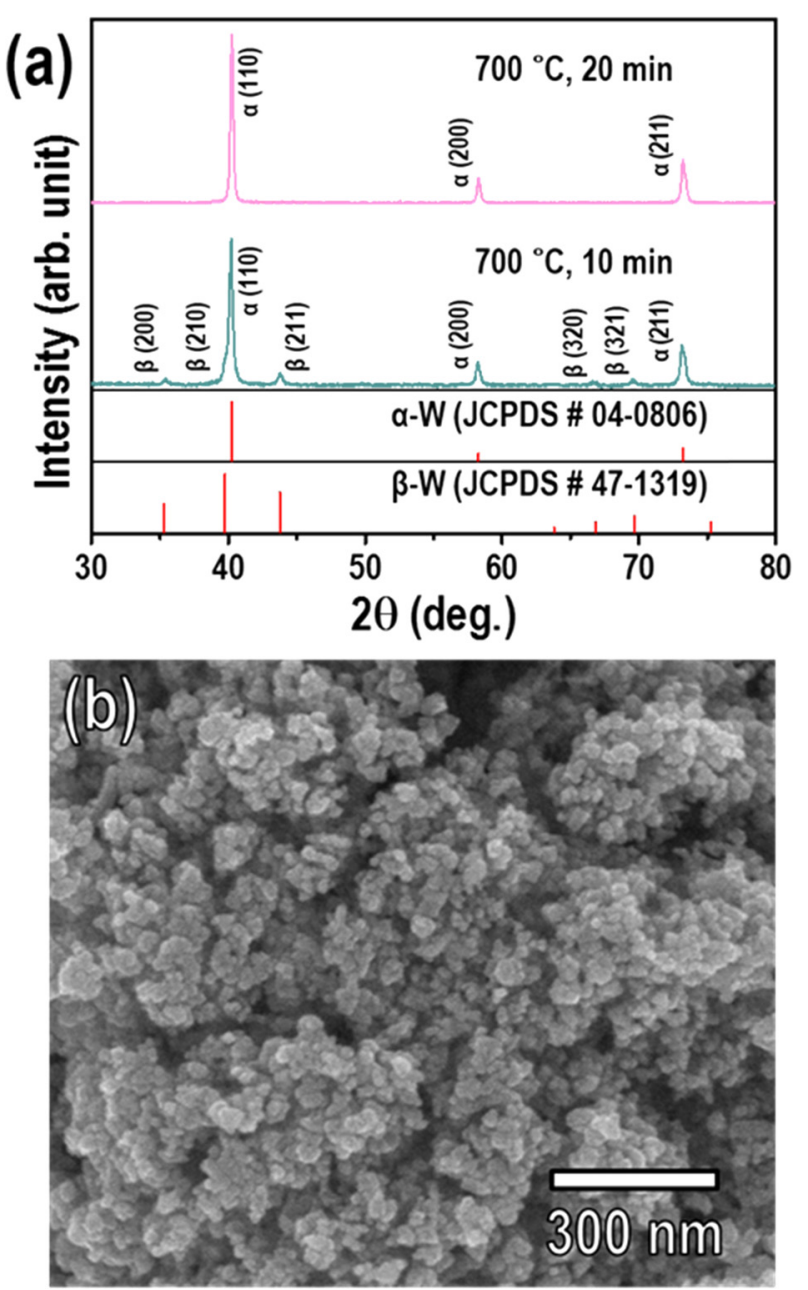

Fig. 9. (a) XRD patterns of powders reduced at $700{ }^{\circ} \mathrm{C}$ for $10 \mathrm{~min}$ and $20 \mathrm{~min}$ from the mixed-phase $\alpha$ - and $\beta$-W nanopowder synthesized using RF induction thermal plasma, and (b) FESEM image of the powder reduced at $700{ }^{\circ} \mathrm{C}$ for $20 \mathrm{~min}$.

induction thermal plasma under Ar sheath gas balanced with $10 \% \mathrm{H}_{2}$, corresponding to Fig. $3 \mathrm{~b}$ and Fig. $4 \mathrm{~b}$, were annealed in an $\mathrm{H}_{2}$ atmosphere (flow rate of $\mathrm{H}_{2}=0.5 \mathrm{~L} / \mathrm{min}$ ) at $700^{\circ} \mathrm{C}$ for $10 \mathrm{~min}$ and $20 \mathrm{~min}$. When the mixed-phase $\mathrm{W}$ nanopowder was reduced by annealing at $700{ }^{\circ} \mathrm{C}$ for $10 \mathrm{~min}$, the $\beta$-W phase was not completely transformed into the $\alpha-\mathrm{W}$ phase, and the sample exhibited a phase mixture. The proportion of $\beta-\mathrm{W}$ phase in the $\mathrm{W}$ nanopowder decreased from $26 \%$ to $11 \%$, as shown in Fig. 9a. When the annealing time was increased to $20 \mathrm{~min}$, the resulting XRD pattern could be indexed to the $\alpha$ $\mathrm{W}$ phase without any $\beta$-W phase (Fig. 9a), indicating the formation of single-phase $\alpha-\mathrm{W}$ nanopowder with a particle size similar to that of the initial mixed-phase W nanopowder (Fig. 9b). This means obtaining single-phase $\alpha-W$ nanopowder by the thermochemical reduction of mixed-phase $\alpha$ - and $\beta-\mathrm{W}$ nanopowder requires a remarkably longer annealing time compared with $\mathrm{WO}_{3}$ nanopowder. It also confirms that the $\beta$ $\mathrm{W}$ phase of $\mathrm{W}$ nanopowder can be transformed into the $\alpha-\mathrm{W}$ phase by thermochemical reduction without changing the particle size.

These results demonstrate that employing the RF induction thermal plasma process with APT micro powder as the precursor and $\mathrm{Ar}$ sheath gas without $\mathrm{H}_{2}$ followed by thermochemical reduction was a more economical and facile method for the synthesis of single-phase $\alpha-\mathrm{W}$ nanopowder than the thermal plasma treatment using $10 \% \mathrm{H}_{2}$ in the sheath gas, because of its lower energy consumption and shorter annealing time. In other words, to fabricate the single-phase $\alpha$ $\mathrm{W}$ nanopowder, converting $\mathrm{WO}_{3}$ nanopowder synthesized from APT into single-phase $\alpha-\mathrm{W}$ was better than transforming mixed-phase $\alpha$ - and $\beta$-W nanopowder. Also, compared with the reported synthesis of single-phase $\alpha-\mathrm{W}$ nanopowder $[3,6-8$, 24], in the present approach particle size can be easily controlled by annealing temperature, the morphology is spherical, and the dispersive condition is equal or superior since there is no remarkable aggregation.

\section{CONCLUSIONS}

The material process engineering challenges of pure singlephase $\mathrm{W}$ nanopowder synthesis has been addressed through a two-stage process. $\mathrm{WO}_{3}$ powder was produced from commercially available APT through RF induction plasma treatment and commercial-grade single-phase $\alpha-\mathrm{W}$ nanopowder was then produced by thermochemical reduction at $700{ }^{\circ} \mathrm{C}$ for $10 \mathrm{~min}$. Unlike our previously reported $\mathrm{W}$ powder synthesis [23], in the current study the $\mathrm{WO}_{3}$ nanopowder synthesized from ATP in the first step was completely transformed into single-phase $\alpha-\mathrm{W}$. Experiments determined that the synthesis of single-phase $\alpha-\mathrm{W}$ nanopowder from mixed-phase $\alpha$ - and $\beta-\mathrm{W}$ nanopowder required a longer annealing time (20 min), a relatively energy-intensive process without any remarkable improvement in particle size. These results indicate that the synthesis of single-phase $\alpha-\mathrm{W}$ nanopowder using $\mathrm{WO}_{3}$ nanopowder is a more economical and facile method than using mixed-phase $\alpha$ - and $\beta-\mathrm{W}$ nanopowder. The synthetic strategy 
proposed in this study to produce single-phase $\alpha-\mathrm{W}$ nanopowder can also open new avenues for the preparation of other refractory metal nanopowders, such as Ta, Mo, and $\mathrm{Zr}$.

\section{ACKNOWLEDGMENT}

This study was supported by the Korea Institute of Energy Technology Evaluation and Planning (KETEP), which is funded by the Ministry of Trade, Industry and Energy, the Republic of Korea (No. 20152510101950).

\section{REFERENCES}

1. Nanoshel LLC, Tungsten Nanoparticle Application, https:// www.nanoshel.com/tungsten-nanoparticles-application (2017).

2. E. Lassner and W. D. Schubert, Tungsten: Properties, Chemistry, Technology of the Element, Alloys, and Chemical Compounds, p.133, Springer, US (2012).

3. Y. Han, J. Fan, T. Liu, H. Cheng, and J. Tian, Int. J. Refract. Met. Hard Mater. 29, 743 (2011).

4. E. Oda, K. Ameyama, and S. Yamaguchi, Mater. Sci. Forum 503-504, 573 (2006).

5. R. Ricceri and P. Matteazzi, J. Alloys Compd. 358, 71 (2003).

6. P. K. Sahoo, S. S. Kalyan Kamal, M. Premkumar, T. Jagadeesh Kumar, B. Sreedhar, A. K. Singh, S. K. Srivastava, and K. Chandra Sekhar, Int. J. Refract. Met. Hard Mater. 27, 784 (2009).

7. G. Si, X. Xi, Z. Nie, L. Zhang, and L. Ma, Int. J. Refract. Met. Hard Mater. 54, 422 (2016)

8. M. Qin, Z. Chen, P. Chen, S. Zhao, R. Li, J. Ma, and X. Qu, Int. J. Refract. Met. Hard Mater. 68, 145 (2017).

9. T. Rodriguez-Suarez, L. A. Diaz, S. Lopez-Esteban, C. Pecharroman, A. Esteban-Cubillo, L. Gremillard, R. Torrecillas, and J. S. Moya, Nanotechnology 19, 215605 (2008).

10. G. Singla, K. Singh, and O. P. Pandey, Powder Technol. 237, 9 (2013).

11. T. Sarmah, N. Aomoa, G. Bhattacharjee, S. Sarma, B. Bora, D. N. Srivastava, H. Bhuyan, M. Kakati, and G. de Temmerman, J. Alloys Compd. 725, 606 (2017).

12. T. Ryu, H. Y. Sohn, K. S. Hwang, and Z. Z. Fang, Int. J.
Refract. Met. Hard Mater. 27, 149 (2009).

13. P. V. Krasovskii, A. V. Samokhin, and O. S. Malinovskaya, Powder Technol. 286, 144 (2015).

14. R. K. Enneti, Int. J. Refract. Met. Hard Mater. 53, 111 (2015).

15. M. I. Boulos, IEEE Trans. Plasma Sci. 19, 1078 (1991).

16. M. Boulos, Met. Powder Rep. 59, 16 (2004).

17. H. Zhang, L. Bai, P. Hu, F. Yuan, and J. Li, Int. J. Refract. Met. Hard Mater. 31, 33 (2012).

18. J. J. Wang, J. J. Hao, Z. M. Guo, and Y. M. Wang, Rare Met. 34, 431 (2015).

19. K. S. Kim, A. Moradian, J. Mostaghimi, Y. Alinejad, A. Shahverdi, B. Simard, and G. Soucy, Nano Res. 2, 800 (2009).

20. C. Han, H. Na, Y. Kim, and H. Choi, Int. J. Refract. Met. Hard Mater. 53, 7 (2015).

21. X. L. Jiang and M. Boulos, Trans. Nonferrous Met. Soc. China 16, 13 (2006).

22. F. Liao, S. Park, J. M. Larson, M. R. Zachariah, and S. L. Girshick, Mater. Lett. 57, 1982 (2003).

23. D. Shin, B. Swain, C. Han, Y. Kim, C.-G. Lee, and K.-S. Park, Int. J. Refract. Met. Hard Mater. 86, 104995 (2020).

24. S. S. K. Kamal, P. K. Sahoo, J. Vimala, B. Shanker, P. Ghosal, and L. Durai, J. Alloys Compd. 678, 403 (2016).

25. L. Landström, J. Kokavecz, J. Lu, and P. Heszler, J. Appl. Phys. 95, 4408 (2004).

26. Y. S. Kwon, J. C. Kim, A. P. Ilyin, O. B. Nazarenko, and D. V. Tikhonov, J. Korean Powder Metall. Inst. 19, 49 (2012).

27. T. Acsente, R. F. Negrea, L. C. Nistor, C. Logofatu, E. Matei, R. Birjega, C. Grisolia, and G. Dinescu, Eur. Phys. J. D 69, 161 (2015).

28. S. Zhang, Y. Wen, and H. Zhang, Powder Technol. 253, 464 (2014).

29. A. K. Basu and F. R. Sale, J. Mater. Sci. 12, 1115 (1977).

30. M. J. G. Fait, H. J. Lunk, M. Feist, M. Schneider, J. N. Dann, and T. A. Frisk, Thermochim. Acta 469, 12 (2008).

31. Y. G. Shen and Y. W. Mai, Mater. Sci. Eng. A 284, 176 (2000).

32. E. Hegedus, J. Neugebauer, and M. Meszaros, Int. J. Refract. Met. Hard Mater. 16, 31 (1998).

33. J. S. Lee, J. Cho, and C. Y. You, J. Vac. Sci. Technol. A 34, 021502 (2016).

34. F. Zhu, Z. Xie, and Z. Zhang, AIP Adv. 8, 035321 (2018). 